\title{
Biodiversity law has had some unintended effects
}

\section{Moves to prevent unfair exploitation of resources could restrict conservation research.}

Sir - Your News story "Bioprospectors

hunt for fair share of profits" (Nature 427, 576 ; 2004) correctly draws attention to the bureaucratic impediments many countries have placed in the way of access to biodiversity in the wake of the Convention on Biological Diversity (CBD, 1992). It reveals that delays in developing benefitsharing agreements are retarding the potential of biodiversity-rich countries to reap the full rewards of biotechnology. However, by overvaluing the commercial potential of biodiversity, CBD-based legislation in these countries is also impeding conservation science.

There was much hope after the CBD that developing countries would conserve biodiversity for its economic promise, specifically the potential pharmaceutical profits derived from biological resources. Such resources were called 'green gold', and these countries have been told, for example, that "people all over the world last year paid more than $\$ 400$ billion for pharmaceuticals, nearly half of which were discovered in the wild" (D. Labrador Sci. Am. 289, 17-18; December 2003). The media continue to publicize the handful of glamorous examples of medicines obtained from tropical biodiversity - such as the appetite-suppressant properties of the Kalahari plant Hoodia gordonii.

Such hype has not been lost on the governments of developing countries, who have concluded that billions of 'eco-dollars' lie hidden in their forests. Understandably, they have responded by hastily framing laws to protect (rather than conserve) their biodiversity. Although they are mostly intended to facilitate access, many of these laws obstruct biodiversity-related research, rarely differentiating between commercial and conservation science. Meanwhile, commercial returns from benefit-sharing in these countries remain trivial compared with their national conservation budgets.

One of the first scientific victims of these restrictive regimes is taxonomy. Fewer than 10\% of the species on Earth have been described, but access legislation in many developing countries alienates and criminalizes taxonomists, whose job it is to describe them. For example, regulations made under India's Biological Diversity Act, passed in 2002, require any person wishing to have "access to biological resources and associated knowledge for research" to seek government approval, paying an exorbitant US\$200 application fee (India's annual gross national income per capita is $\$ 460$, according to the World Bank).

The adverse impact of the CBD on research is finally being more widely recognized. The International Union of Biological Sciences, at its 28th general assembly in Cairo in January 2004, having debated these issues at a one-day workshop, resolved to promote "activities that enhance scientific input to the CBD process". These include the results of biodiversity inventories and population studies based on field exploration, which require access to the species concerned.

For many biologists working in developing countries, however, the jury is still out on whether the unintended negative consequences of the CBD outweigh its benefits.

Rohan Pethiyagoda

Adviser to the Ministry of Environment and Natural Resources, Sampathpaya,

Battaramulla, Sri Lanka

\section{Putting Norway on the gene-therapy map}

Sir - I read with interest the Commentary by M. Cavazzana-Calvo and colleagues on "The future of gene therapy" (Nature 427, 779-781; 2004). However, readers should be aware that the statistics used to produce the map shown on page 781, "Number of approved gene-therapy trials", are incomplete.

The map, using data compiled from available sources by the Wiley Journal of Gene Medicine, indicated that no genetherapy trials have been performed in Norway. Yet, according to the Norwegian Directorate of Health, which approves such studies, seven trials were performed before 2004 - six at the Norwegian Radium Hospital and one at the National Hospital, both in Oslo.

For Norway, this is not just a question of incomplete statistics. When the first application for a gene-therapy trial was rejected by the Norwegian Board of Health in 1996, on the basis of sound scientific advice, rumours circulated in the international community that Norwegian authorities were hostile towards gene therapy. Your map supports this impression. Yet, during the past five years the Norwegian Ministry of Health has funded an ambitious grant programme to help scientists in Norway acquire internationally competitive competence in gene therapy.

Some years ago, I participated in a technology-assessment study of gene therapy organized by the Norwegian Center for Health Technology Assessment, in which the Wiley, Medline, EMBASE and US National Institutes of Health databases were searched for information on clinical trials. This resulted in a much more complete survey, although there is still no single authoritative source for such information. Ola Myklebost

Department of Tumour Biology, Norwegian Radium Hospital,

N-0310 Oslo, Norway

\section{Gene therapy needs both trials and new strategies}

Sir - In their Commentary "The future of gene therapy" (Nature 427, 779-781; 2004), M. Cavazzana-Calvo and colleagues suggest that we proposed, in a recent Perspectives article (Science 302, 400-401; 2003), screening genetically modified stem cells before they are infused into patients, to avoid potential serious side effects.

We are very much aware that such an approach is not applicable with current methods. Our comment represented our vision of where the field needs to move in the future. To thrive, the field needs both continuous development of realistic clinical trials - as outlined by CavazzanaCalvo and colleagues - and conceptual discussions about new strategies. Regulatory decisions need to follow the former, scientific the latter.

As outlined in the Perspectives article, advanced cell culture, gene delivery and molecular screening technologies are likely to bring significant progress in the foreseeable future.

David Williams*, Christopher Baum ${ }^{\star} \dagger$

${ }^{\star}$ Cincinnati Children's Hospital Medical Center, Division of Experimental Hematology,

3333 Burnet Avenue, Cincinnati,

Ohio 45229-3039, USA

$\dagger$ Hannover Medical School, Department of Hematology, Hemostaseology and Oncology, Carl-Neuberg-Strasse 1,

30625 Hannover, Germany

\section{correspondence}

Contributions to Correspondence may be submitted to corres@nature.com. They should be no longer than 500 words, and ideally shorter. Published contributions are edited. 